\title{
Identification of Common Trends in Prices, Demand and Supply of Natural Rubber: An Approach Using Dynamic Factor Model
}

\author{
Keminda Herath ${ }^{*}$, S. Samita ${ }^{1}$ and Wasana Wijesuriya ${ }^{2}$ \\ Postgraduate Institute of Agriculture \\ University of Peradeniya \\ Peradeniya, Sri Lanka
}

\begin{abstract}
Natural Rubber (NR) an agricultural product is an important raw material in a broad spectrum of industries such as automobile and pharmaceutical. NR sector has its local and global dimensions. Hence, understanding the dynamic nature of common trends in demand, supply and prices of NR and their interactions with other important factors is vital for the sustainable growth of this sector. This study aims at finding common trends in a multivariate time series and their interaction with explanatory variables using a technique called Dynamic Factor Analysis (DFA) since the conventional time series methods are not capable of handling this kind of analysis. To elaborate the applicability of DFA, four case studies are presented namely, i) world NR production, ii) world NR consumption, iii) NR prices in Sri Lanka and iv) NR prices at international market. Practical issues in selection of models based on AIC are discussed with solutions, which includes a test based on change in log likelihood. This study provides empirical evidences on selecting models based on the proposed method of model selection.
\end{abstract}

Keywords: Dynamic factor analysis (DFA), NR prices, demand and supply

\section{INTRODUCTION}

Raw rubber is an important agricultural commodity which is a vital raw material for various types of industries viz. tire manufacture, toy making, and manufacture of rubber based surgical equipment. The increasing trend in Natural Rubber (NR) prices ruling over the past several years is due to the world's steady NR demand and persistent NR supply tightness. The supply tightness is mainly due to highly variable and unpredictable climatic disfavors. Rising crude oil price abetted the rise in NR prices by influencing the demand for Synthetic Rubber (SR). Ample demand for NR is mainly due to the persistent growth of NR based industries in China (Rubber Asia, 2010). Being a key plantation crop, rubber contributes significantly to their GDPs of rubber growing countries in Asia. There are about 24 countries reported contributing significantly to the world NR production of which about $90 \%$ is contributed by six key countries viz. Thailand, Indonesia, Malaysia, India, Vietnam and China (IRSG, 2010). Consequently, they have a control over the world NR market, while rest of the countries have become price takers. Consequently, NR prices in their local markets are more volatile to NR prices at the international market. Further, large numbers of livelihoods

Department, of Crop Science, Faculty of Agriculture, University of Peradeniya, Sri Lanka

Biometry Section, Rubber Research Institute, Agalawatta, Sri Lanka

Author for correspondence: dulsara@vt.edu 
are either directly or indirectly engaged in the rubber sector, which has become a key source in their social and economic status. Hence, it is very important to understand both global and

local trends and interactions of key economic indicators in the NR sector, which support the decision making process for sustainable development of both NR producers and consumers.

Univariate time series models such as ARIMA models, box-Jenkins models (Chatfield, 2000), Spectral analysis (Priestely, 1981) and wavelet analysis (Shumway and Stoffer, 2006) are the most common methods used to study the dynamic behavior of the trends in different time series. Although, the above mentioned models are good enough to study the pattern (trends or cycles) in a specific time series; they are not capable of identifying the general pattern/s and interactions of several variables measured in time which is our foremost interest in this study. State space models are capable of handling non-stationary short multivariate time series data (Durbin and Koopman, 2004). Further, it can be used to identify common signals reflected by some multivariate time series where it is viewed as an incomplete data problem.

Dynamic Factor Model (DFM) can be viewed as a further refinement of the state space model, which aims at modeling $\mathrm{N}$ observed time series in terms of $\mathrm{M}$ common trends $(\mathrm{N}<\mathrm{M})$. This resembles a Factor Analysis $(\mathrm{FA})$ where the axes are restricted to be latent smoothing functions over time (Zuur et al., 2003). It is an advantage that, covariates can be included in this model while missing values are also tractable in it. But, parameter estimation by a simple estimator is not realistic with DFM. Since trend component of the model is not known, parameter estimation by direct optimization of the complete data likelihood function is also not possible. However, it can be easily satisfied with the EM algorithm (Molenaar et al., 1992; Zuur et al., 2003; Shumway and Stoffer, 2006).

Dynamic Factor Analysis (DFA) is very useful in econometric analysis; especially providing opportunities to use common trends as indicators of some economic parameters. Also, it can be viewed as an alternative to the vector autoregression (Macho, 1997). Further, DFA has been used in many psychology related studies where model parameters have been estimated by direct numerical optimization of a maximum likelihood criterion (Molenaar et al., 1992). Less number of time series variables have been used in these studies since direct numerical optimization becomes complicated and time consuming when the parameters to be estimated become greater in number. Parameter estimation can also be done by a Bayesian approach using a Markov chain Monte Carlo (West and Harrison, 1997) for which a fairly long time series is required. Maximum likelihood estimates of the hyper parameters of a state space model can be obtained by both Newton-Raphson algorithm and Expected Maximization (EM) algorithm together with Kalman filter (Shumway and Stoffer, 2006). Zuur et al. 2003 have comprehensively studied estimation of common trends in multivariate time series using DFA where parameter estimation has been carried out by the EM algorithm and Kalman filter. However, in DFA, procedures for model selection, determination of the number of common trends and their interpretability are not very clearly defined. This may leave the general user of DFM confused.

This study aims at coming up with some important tips that helps the user of DFA in selection of a model with reasonably interpretable common trends. Procedures of model selection and validation of common trends are illustrated using several sets of real data from the NR sector in Global and Local contexts. 


\section{METHODOLOGY}

\section{Dynamic factor model (DFM)}

DFM is a structural time series model consisting of trend, covariates and noise as its components (Zuur et al., 2003). The model can be presented in matrix notation as;

$$
\begin{aligned}
& \mathrm{y}_{\mathrm{t}}=\Lambda \mathrm{z}_{\mathrm{t}}+\mathrm{Bx}_{\mathrm{t}}+\mathrm{u}_{\mathrm{t}} \\
& z_{t}=z_{t-1}+v_{t}
\end{aligned}
$$

where, $y_{t}$ is a $N \times 1$ vector of observations and $x_{1}$ is a $K \times 1$ vector of covariates (explanatory variables) at time t. $\Lambda$ is a matrix of dimension $\mathrm{N} \times \mathrm{M}$ that contain factor loadings while $\mathrm{z}_{1}$ is a $1 \times \mathrm{M}$ vector of common trends at time $\mathrm{t},(\mathrm{t}=1,2, \ldots.) . \mathrm{u}_{\mathrm{t}}$ and $v_{t}$ are vectors of noises. It is generally assumed that $u_{t} \sim n(0, R), v_{t} \sim n(0, H)$ and $z_{0} \sim n\left(b_{0}, S_{0}\right)$. $\mathrm{u}_{\mathrm{t}}, v_{t}$ and $\mathrm{z}_{0}$ are independent. $\Lambda, \mathrm{B}, \mathrm{H}, \mathrm{R}, \mathrm{b}_{0}$ and $\mathrm{S}_{0}$ are the hyper-parameters to be estimated in DFA. Consequently, the variance of $\mathrm{y}_{\mathrm{t}}$ is $\Lambda \operatorname{var}\left(z_{t}\right) \Lambda^{\prime}+R$, which is similar to the form of variance of observations in FA. It can be noticed that the formula (1) in the absence of explanatory variables resembles the functional form of explanatory FA. However, in the context of a state space models, (1) is said to be the observation equation while (2) is termed as the state equation (unobserved part). The equation (1) can be rewritten as

$$
y_{t}=\theta a_{t}+u_{t}
$$

where, $\theta=[\Lambda, \mathrm{B}]$ and $a_{t}=\left(z_{t}, x_{t}\right)^{\prime}$. Maximum Likelihood Estimates (MLE) of hyper parameters in model 2 and 3 were obtained using EM algorithm and Kalman filter (Shumway et al., 2006, Zuur et al., 2003). ME algorithm successively maximizes the conditional expectation of the complete data likelihood. The complete data likelihood and conditional expectation on hyper parameters at $(\mathrm{i}-1)^{\text {th }}$ iteration are illustrated in equations 4 and 5 , respectively (Shumway et al., 2000). $\Omega^{\mathrm{i}-1}$ contains all hyper parameters estimated at $(\mathrm{i}-1)^{\text {th }}$ iteration.

$$
\begin{aligned}
\ln \mathrm{L}\left(\mathrm{y}_{1}, \ldots \ldots \mathrm{y}_{\mathrm{T}}, \mathrm{z}_{0}, \mathrm{z}_{1} \ldots . \mathrm{z}_{\mathrm{T}}\right)= & -\frac{1}{2} \ln \left|\mathrm{S}_{0}\right|-\frac{1}{2}\left(\mathrm{z}_{0}-\mathrm{b}_{0}\right)^{\prime} \mathrm{S}_{0}^{-1}\left(\mathrm{z}_{0}-\mathrm{b}_{0}\right)-\frac{\mathrm{T}}{2} \ln |\mathrm{H}| \\
& -\frac{1}{2} \sum_{\mathrm{t}-1}^{\mathrm{T}}\left(\mathrm{z}_{\mathrm{t}}-\mathrm{z}_{\mathrm{t}-1}\right)^{\prime} \mathrm{H}^{-1}\left(\mathrm{z}_{\mathrm{t}}-\mathrm{z}_{\mathrm{t}-1}\right)-\frac{\mathrm{T}}{2}|\mathrm{R}| \\
& -\frac{1}{2} \sum_{\mathrm{t}=1}^{\mathrm{T}}\left(\mathrm{y}_{\mathrm{t}}-\theta \mathrm{a}_{\mathrm{t}}\right)^{\prime} \mathrm{R}^{-1}\left(\mathrm{y}_{\mathrm{t}}-\theta \mathrm{a}_{\mathrm{t}}\right)+\mathrm{k}
\end{aligned}
$$

$\mathrm{E}\left(\ln \mathrm{L}\left(\mathrm{y}_{1}, \ldots, \mathrm{y}_{\mathrm{T}}, \mathrm{z}_{0}, \ldots, \mathrm{z}_{\mathrm{T}}\right)\left|\mathrm{y}_{1}, \ldots ., \mathrm{y}_{\mathrm{T}}\right| \Omega^{\mathrm{i}-1}\right)=$

$$
\begin{aligned}
& -\frac{1}{2} \ln \left|\mathrm{S}_{0}\right|-\frac{1}{2} \operatorname{tr}\left\{\mathrm{S}_{0}^{-1}\left(\mathrm{~S}_{0 \mid \mathrm{T}}+\left(\mathrm{z}_{0}-\mathrm{b}_{0}\right)\left(\mathrm{z}_{0}-\mathrm{b}_{0}\right)^{\prime}\right)\right\} \\
& -\frac{1}{2} \ln |\mathrm{H}|-\frac{1}{2} \operatorname{tr}\left\{\mathrm{H}^{-1}\left(\mathrm{P}_{1}-2 \mathrm{P}_{2}+\mathrm{P}_{3}\right)\right\} \\
& -\frac{1}{2} \ln |\mathrm{R}|-\frac{1}{2} \operatorname{tr}\left\{\mathrm{R}^{-1} \frac{1}{2} \sum_{\mathrm{t}=1}^{\mathrm{T}}\left(\left(\mathrm{y}_{\mathrm{t}}-\theta \mathrm{a}_{\mathrm{t}}\right)\left(\mathrm{y}_{\mathrm{t}}-\theta \mathrm{a}_{\mathrm{t}}\right)^{\prime}+\Lambda \mathrm{S}_{\mathrm{t} \mathrm{T}} \Lambda^{\prime}\right)\right\}^{-\cdots----}
\end{aligned}
$$

where, $P_{1}=\sum_{t=1}^{T}\left(z_{t \mid T} z_{t \mid T}^{\prime}+S_{t \mid T}\right), P_{2}=\sum_{t=1}^{T}\left(z_{t \mid T} z_{t-1 \mid T}^{\prime}+S_{t, t-1 \mid T}\right), P_{3}=\sum_{t=1}^{T}\left(z_{t-1 \mid T} z_{t-1 \mid T}^{\prime}+v_{t-1 \mid T}\right)$. 
$\mathrm{z}_{\mathrm{tT}}$ and $\mathrm{S}_{\mathrm{tTT}}$ are the best linear estimators of $\mathrm{z}_{\mathrm{t}}$ and variance of $\mathrm{z}_{\mathrm{t}}$, respectively. $\mathrm{S}_{\mathrm{t}, \mathrm{t}-1 \mathrm{~T}}$ is the variance covariance matrix of $z_{\mathrm{t} \mid \mathrm{T}}$ and $\mathrm{z}_{\mathrm{t}, \mathrm{t}-\mathrm{T} \mathrm{T}}$. Moreover, all of these were estimated with the

Kalman filter, which was applied to equations (1) and (2) at the E-step in the EM algorithm (Shumway et al., 2006). Further, by applying basic calculus on (5), it can be shown that (5) is maximized when,

$$
\begin{aligned}
& \theta=\left[\begin{array}{ll}
\sum_{t-1}^{T} y_{t} z_{t \mid T}^{\prime} & \sum_{t-1}^{T} y_{t} x_{t}^{\prime}
\end{array}\right] G^{-1}, \text { where } \\
& G=\left[\begin{array}{cc}
\sum_{t=1}^{T} z_{t \mid T} z_{t \mid T}^{\prime}+S_{t \mid T} & \sum_{t=1}^{T} z_{t \mid T} x_{t}^{\prime} \\
\sum_{t=1}^{T} x_{t} z_{t \mid T}^{\prime} & \sum_{t=1}^{T} x_{t} x_{t}^{\prime}
\end{array}\right]
\end{aligned}
$$

$\theta$ is updated at the M step of the EM algorithm. Standard errors of $\Gamma$ was calculated by bootstrapping (1) and (2) (Shumway et al., 2006). All statistical computations were done using R 2.12.1 and BRODGAR 2.5.1.

\section{Unique estimates for factor loadings and common trends}

DFM is not identifiable (Molenaar et al., 1992), which is a common problem in factor analysis also (Rencher, 2002). As done in factor analysis, restrictions were employed on $\Lambda$ and $\mathrm{H}$ in order to get unique estimates for common trends and underlying factor loadings (Zuur, et al., 2003) which gives an insight for factor rotation (varimax rotation) that gives DFM its utility. However there are no such restrictions applied on R, which is the error covariance. It could be either diagonal, symmetric non-diagonal matrix. Depending on the error structure and inclusion of explanatory variables in to the model, different model types can be fitted and the best models can be chosen using an appropriate criterion of goodness of fit. There is no matter of using either uniform covariance or not since Zuur et al. (2003) have shown that $\mathrm{R}$ can be updated even with off diagonal elements. However, uniformity in the covariance may lead to more stable algorithms.

\section{Model Selection}

In DFA, models are usually selected based on a goodness of fit criteria viz. AIC (Akaike, 1987), which compromise both likelihood and the number of parameters estimated in the model (Molenaar, 1992, Zuur et al., 2003 and Shumway et al., 2006). The model with least AIC will be the best fitted model for the underlying data. At the same time it is important to maintain lesser number of common trends without loosing much information (Zuur, 2003). Practically, the best fit model has more common trends, which are not interpretable some times. There will be another model with slightly higher AIC and more meaningful common trends. However, it will be identified as a misfit if the model selection is done merely based on AIC. In this study the significance of change in likelihood between models together with AIC is proposed to be used for testing the goodness of fit. Let;

$$
\ln \left(\mathrm{L}_{\mathrm{m} 1}\right)=\ln \mathrm{L}\left(\mathrm{y}_{1} \ldots \mathrm{y}_{\mathrm{N}} / \mathrm{z}_{1} \ldots \mathrm{z}_{\mathrm{m} 1}\right)
$$

The change in likelihood $(\Delta G)$ is defines as,

$$
\Delta G=\ln \left(L_{m 1}\right)-\ln \left(L_{m 2}\right) \text {, where } \ln \left(\mathrm{L}_{\mathrm{m} 2}\right)=\ln \mathrm{L}\left(\mathrm{y}_{1} \ldots \mathrm{y}_{\mathrm{N}} / \mathrm{z}_{1} \ldots \mathrm{z}_{\mathrm{m} 2}\right) .
$$

Under $\mathrm{H}_{0}$, it can be shown that $-2 \Delta G \sim \chi_{p-q}^{2}$, where $p-q$ is the difference between error degrees of freedom of two models under the investigation (Rice, 2007). 


\section{Data used to test the proposed method}

Evidence for the usefulness of the proposed methodology is illustrated by applying it on several empirical examples from the NR sector. They were (i) world supply of NR by major NR producing countries, (ii) world demand for NR by major NR consuming countries, (iii) prices of NR at International markets and (iv) local auction prices of NR in Sri Lanka. The sources of data were statistical bulletins published quarterly by the International Rubber Study Group (IRSG) and statistical pocket book published annually by the Ministry of Plantation Industries (MPI) of Sri Lanka. Monthly data on each variable for the period from 2000 to 2010 were used in the model fitting.

\section{RESULTS AND DISCUSSION}

\section{Case study 1: World NR Production}

Brazil, Côte d'Ivoire, China, India, Indonesia, Malaysia, Philippines, Sri Lanka, Thailand and Vietnam have contributed to more than $85 \%$ of the total world supply of NR for the period between 2000 and 2010. Model diagnostics for different DFMs fitted to monthly NR production figures of major NR producing countries are listed in Table 1. Model with four common trends (symmetric non diagonal R) has the lowest AIC among the other models. This model can be accepted since given common trends are coherent. If the Change in log likelihood between the selected model (model with least AIC) and other models ( $\left.\Delta G^{*}\right)$ is considered, then it can be noticed that the same model with four common trends in Table 1 can be accepted as the best fitted model. This is an ideal example that the test based on the $\Delta \mathrm{G}^{*}$ and $\mathrm{AIC}$ selects the same model which has meaningful common trends.

Table 1. Model diagnostics for DFMs with different common trends and $R$ fitted to monthly NR production figures of world major NR producing countries

\begin{tabular}{cccccc}
\hline $\begin{array}{c}\text { Common } \\
\text { trends(M) }\end{array}$ & AIC & $\begin{array}{c}\text { Log } \\
\text { likelihood }\end{array}$ & $\begin{array}{c}\text { No of } \\
\text { parameters }\end{array}$ & $\Delta \mathrm{G}^{*}$ & $\mathrm{p}(\geq 2 \Delta \mathrm{G})$ \\
\hline \multicolumn{7}{l}{ Model I: M } & common trends & + Noise; & \multicolumn{2}{c}{$R$-Symmetric } & Non-diagonal & \\
1 & 2478.83 & -1164.42 & 75 & 187.82 & $<0.000$ \\
2 & 2353.15 & -1092.57 & 84 & 115.97 & $<0.000$ \\
3 & 2256.36 & -1036.18 & 92 & 59.58 & $<0.000$ \\
$\mathrm{~b}_{4}$ & 2151.20 & -976.60 & 99 & & \\
5 & 2240.18 & -1015.09 & 105 & 38.49 & $<0.000$ \\
Model II: M common trends + Noise; & $R-$ Diagonal & & \\
1 & 2688.27 & -1314.13 & 30 & 337.53 & $<0.000$ \\
2 & 2486.78 & -1204.39 & 39 & 227.79 & $<0.000$ \\
3 & 2615.68 & -1260.84 & 47 & 284.24 & $<0.000$ \\
\hline
\end{tabular}

${ }^{\mathrm{b}}$ selected as best fitted model., $\Delta \mathrm{G}$ " is defined as the change of log likelihood between the selected model and other models

Fig. 1.depicts four common trends in NR production among world leading NR producing countries, which were identified by the best fitted model given in Table1. Relevant factor loadings after varimax rotation are given in Table 2. 


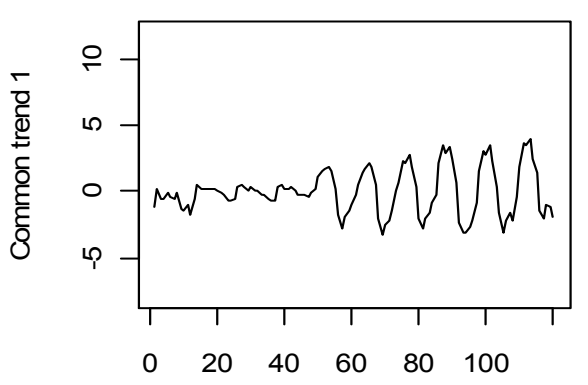

Time (months from Jan 2000)

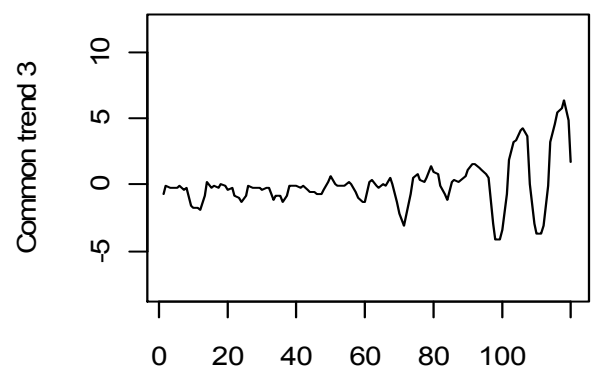

Time (months from Jan 2000)

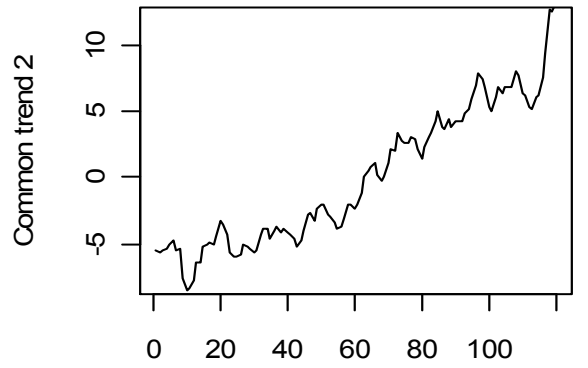

Time (months from Jan 2000)

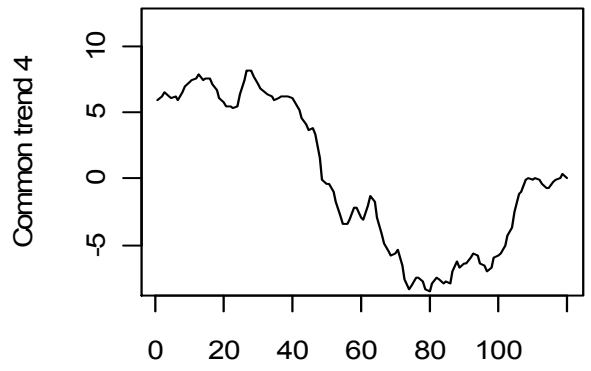

Time (months from Jan 2000)

Fig. 1. Common trends in NR production among world leading NR producing countries

Table 2. Factor loadings associated with respective common trends of world NR production

\begin{tabular}{lrccc}
\hline Country & $\begin{array}{c}\text { Common } \\
\text { Trend 1 }\end{array}$ & $\begin{array}{c}\text { Common } \\
\text { Trend 2 }\end{array}$ & $\begin{array}{c}\text { Common } \\
\text { Trend 3 }\end{array}$ & $\begin{array}{c}\text { Common } \\
\text { Trend 4 }\end{array}$ \\
\hline Brazil & 0.487 & 0.080 & -0.082 & 0.006 \\
Côte d' Ivoire & 0.041 & 0.150 & 0.112 & -0.021 \\
China & -0.018 & -0.006 & 0.528 & -0.007 \\
India & -0.404 & 0.103 & -0.126 & -0.015 \\
Indonesia & 0.018 & 0.083 & -0.018 & -0.087 \\
Malaysia & -0.082 & -0.035 & 0.067 & -0.176 \\
Philippines & 0.029 & 0.123 & 0.144 & 0.020 \\
Sri Lanka & 0.098 & 0.197 & -0.093 & 0.031 \\
Thailand & -0.180 & 0.046 & 0.066 & -0.044 \\
Vietnam & -0.273 & 0.107 & 0.224 & 0.009 \\
\hline
\end{tabular}

Brazil, India, Vietnam and Thailand loads significantly higher into the first common trend, by which the seasonal behavior of NR production in those counties is likely to be depicted. It can be found that the negative sign of factor loadings associated with India, Vietnam and Thailand may be due to opposite seasonal behavior of their monthly NR productions compared to that of the Brazilian monthly NR production. This was further confirmed by respective time series plots. Sri Lanka, Côte d' Ivoire, Philippines, Vietnam and India dominates over the second common trend, which indicates the underlying increasing trends apparent in their NR productions for the period under investigation. Third common trend 
indicate the possible signs of stochastic volatility associated with respective time series that has loaded more into the third trend. The behavior of the fourth common trend is difficult to be explained to which both Malaysia and Indonesia provided comparatively higher weights. However, further investigations are needed for further validations of these behaviors prior to use in other applications. There were no such explanatory variables considered in model fitting.

\section{Case study II: World consumption of NR:}

Monthly NR consumption by USA, China, Japan, India, Malaysia, Republic of Korea, Thailand, France, Germany, Brazil were used in this case study. They altogether contribute about $75 \%$ on the average to the world total annual NR consumption. World total synthetic rubber (SR) consumption was considered as a covariate in the model. DFMs fitted to NR consumption of the selected countries and particular model diagnostics are listed in Table 3.

Model with three common trends, diagonal covariance matrix of errors and SR consumption as a covariate will be identified as the best fitted model; if model selection is done based on the least AIC (2009.2). However, for this model the algorithm was not stable and respective common trends were difficult to be interpreted coherently. As the next step we looked at other models near the model with least AIC until a model with some sensible common trends are found. Consequently, it was found that the model with third least AIC (2012.97) show up four common trends which are interpretable coherently. The choice of this model as the best fitted model can be justified by evaluating respective $\Delta \mathrm{G}^{*}$ values, which are defined as changes of likelihood between the selected model and other candidate models. As indicated in Table 3, it can be noticed that the selected model shows statistically significant deviances of $\log$ likelihood from other candidate models. Further, it was found that the algorithm was more stable with this model set up when it was compared with stability of algorithms of other candidate models. It is clear that this is an example which provides empirical evidence for the usefulness of the proposed test based on $\Delta \mathrm{G}^{*}$ for selection of a best fit DFM.

Table 3. Different DFMs fitted to consumptions of NR by leading NR consuming countries and their model diagnostics

\begin{tabular}{|c|c|c|c|c|c|}
\hline $\begin{array}{l}\text { Common } \\
\text { trends(M) }\end{array}$ & AIC & $\begin{array}{c}\text { Log } \\
\text { likelihood }\end{array}$ & $\begin{array}{c}\text { No of } \\
\text { parameters }\end{array}$ & $\Delta G^{*}$ & $p\left(\geq 2 \Delta G^{*}\right)$ \\
\hline \multicolumn{3}{|c|}{ Model I: M common trends + Noise; } & \multicolumn{2}{|c|}{$R-$ Diagonal } & \\
\hline 1 & 2344.87 & -1142.43 & 30 & 244.952 & $<0.000$ \\
\hline 2 & 2103.32 & -1020.80 & 39 & 123.28 & $<0.000$ \\
\hline 3 & 2068.15 & -987.08 & 47 & 89.60 & $<0.000$ \\
\hline 4 & 2050.67 & -988.34 & 54 & 90.86 & $<0.000$ \\
\hline \multicolumn{6}{|c|}{ Model II: $M$ common trends + Explanatory variables + Noise $; R-$ Diagonal } \\
\hline 1 & 2167.01 & -1043.5 & 40 & 146.026 & $<0.000$ \\
\hline 2 & 2051.32 & -976.66 & 49 & 79.18 & $<0.000$ \\
\hline 3 & 2009.2 & -947.60 & 57 & 50.12 & $<0.000$ \\
\hline 4 & 2010.27 & -935.64 & 64 & 38.16 & $<0.000$ \\
\hline \multicolumn{6}{|c|}{$\begin{array}{l}\text { Model III: } \begin{array}{c}\text { M common trends }+ \text { Explanatory variables }+ \text { Noise } ; \\
\text { symmetric }\end{array}-\text { Non diagonal, }\end{array}$} \\
\hline 1 & 2098.65 & -967.42 & 85 & 69.94 & $<0.000$ \\
\hline 2 & 2057.55 & -934.77 & 94 & 37.29 & $<0.000$ \\
\hline 3 & 2015.02 & -905.51 & 102 & 8.03 & 0.025 \\
\hline
\end{tabular}




\begin{tabular}{|c|c|c|c|c|c|}
\hline${ }^{\mathrm{b}} 4$ & 2012.97 & -897.48 & 109 & & \\
\hline 5 & 2018.39 & -894.2 & 115 & -3.28 & 0.359 \\
\hline \multicolumn{6}{|c|}{ Model IV: M common trends + Noise; $R-$ Non diagonal, symmetric } \\
\hline 1 & 2241.27 & -1045.6 & 75 & 148.15 & $<0.000$ \\
\hline 2 & 2129.31 & -980.65 & 84 & 83.17 & $<0.000$ \\
\hline 3 & 2075.43 & -945.72 & 92 & 48.24 & $<0.000$ \\
\hline 4 & 2069.62 & -935.85 & 99 & 38.37 & $<0.000$ \\
\hline 5 & 2074.38 & -940.75 & 105 & 43.27 & $<0.000$ \\
\hline
\end{tabular}

${ }^{b}$ selected as best fitted model., $\Delta \mathrm{G}^{*}$ is defined as the change of log likelihood between the selected model and the other models.

Common trends given by the selected model are illustrated in Fig. 2 while respective factor loadings are listed in Table 4. It can be observed that Japan, France, USA and Germany added more weights (Table 4) into the first common trend (Fig. 2) which shows fairly steady consumption of NR for the period under investigation. Further, the overall drop in NR based industries in these countries during the recent world economic crisis is clearly exemplified by the apparent sudden drop in common trend 1. China, Thailand, India and USA contribute more to the second common trend. However, factor loading given by USA is negative. Increasing second common trend provides evidence for continuous growth of rubber based industries in China, Thailand, and India. Third common trend resembles the NR consumption pattern of Malaysia. However, the behavior of Brazilian NR consumption was difficult to explain since it loaded more or less equally into all common trends except for the second common trend.
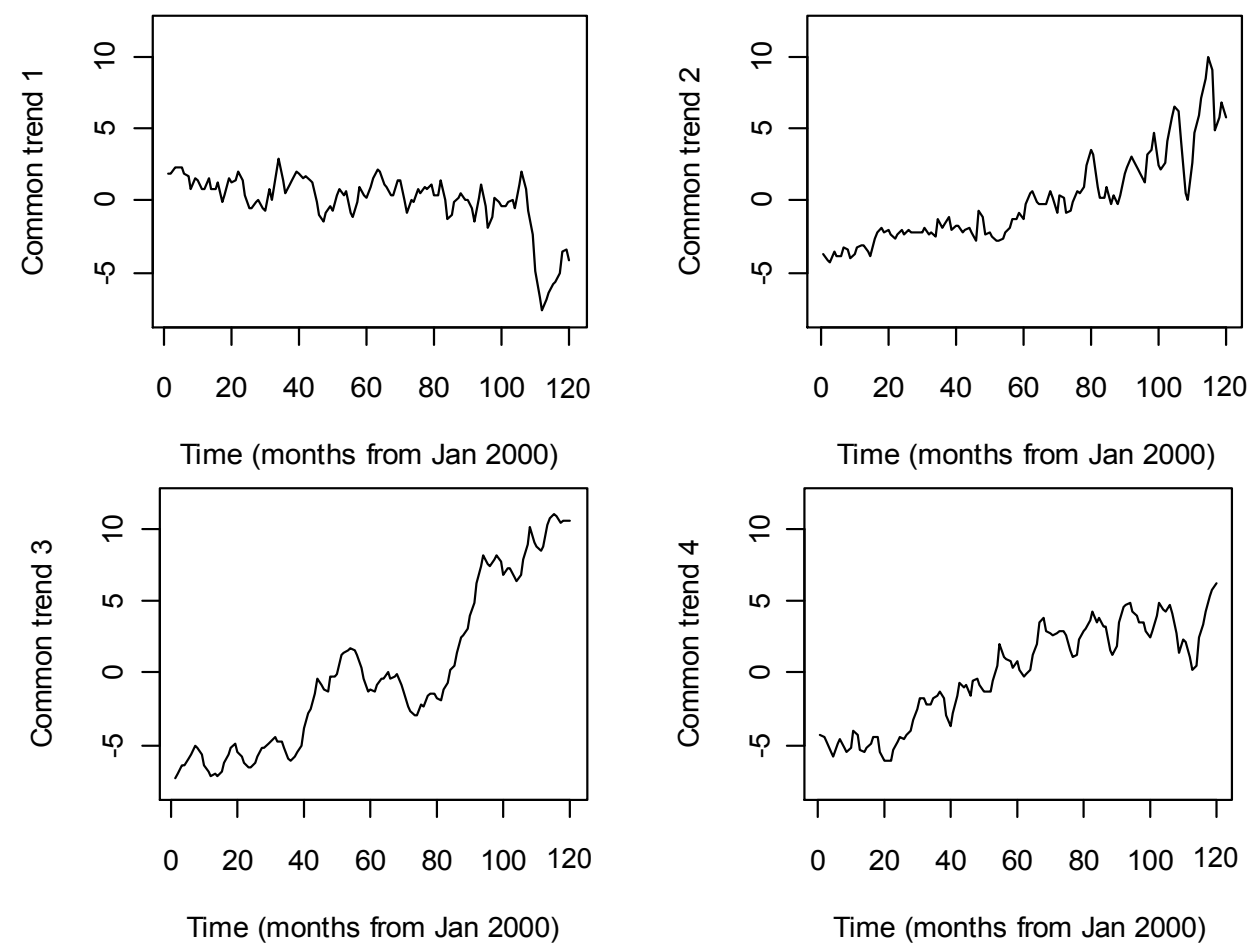

Fig. 2. Identified common trends in NR consumption of countries under the investigation 
Table 4. Factor loadings of respective common trends in the best fit models for consumptions of NR by different countries

\begin{tabular}{lcccc}
\hline Country & Trend 1 & Trend 2 & Trend 3 & Trend 4 \\
\hline USA & 0.295 & -0.157 & 0.014 & 0.027 \\
China & -0.055 & 0.250 & -0.016 & 0.017 \\
Japan & 0.342 & 0.004 & 0.001 & 0.077 \\
India & -0.023 & 0.114 & 0.016 & 0.149 \\
Malaysia & 0.049 & -0.010 & 0.164 & -0.009 \\
R.of Korea & 0.036 & -0.003 & -0.052 & 0.117 \\
Thailand & 0.060 & 0.162 & 0.061 & 0.022 \\
France & 0.319 & -0.035 & 0.011 & -0.114 \\
Germany & 0.148 & -0.098 & -0.094 & 0.036 \\
Brazil & 0.105 & -0.054 & 0.117 & 0.105 \\
\hline
\end{tabular}

World total synthetic rubber (SR) consumption was included as a covariate in the best fitted DFM on NR consumption. Regression coefficients of this covariate together with standard errors and t-values are listed in Table 5. It can be noticed that they are statistically significant with all countries except France. Positive signs of coefficients indicate the positive relationship between world total SR consumption and NR consumption of each country under investigation.

Table 5. Regression coefficients associated with consumption of synthetic rubber included into respective DFM as an explanatory variable.

\begin{tabular}{lccc}
\hline \multirow{2}{*}{ Country } & \multicolumn{3}{c}{ Synthetic rubber (SR) consumption } \\
\cline { 2 - 4 } & Coefficient & s.e & t value \\
\hline USA & 0.20 & 0.09 & $2.28^{*}$ \\
China & 0.25 & 0.04 & $5.94^{* * *}$ \\
Japan & 0.57 & 0.08 & $6.8^{* * *}$ \\
India & 0.09 & 0.04 & $2.15^{*}$ \\
Malaysia & 0.18 & 0.06 & $2.89^{* *}$ \\
R.of Korea & 0.30 & 0.09 & $3.44^{* *}$ \\
Thailand & 0.21 & 0.04 & $4.74^{* * *}$ \\
France & 0.13 & 0.08 & 1.71 \\
Germany & 0.50 & 0.08 & $6.05^{* * *}$ \\
Brazil & 0.21 & 0.07 & $2.79^{* *}$ \\
\hline
\end{tabular}

$*$ - $\mathrm{p}<0.05, * *-\mathrm{p}<0.01, * * *-\mathrm{p}<0.001$

Identification of relationships between economic indicators at local markets and international markets are very important in both global and local level policy implications of the NR sector. It is a common issue that, some important relationships are overwhelmed by some of the other indicators in the sector. However, DFM will be a helpful tool in resolving these ambiguities, when certain indicators are included in to the model as explanatory variables. For example, relationships between Golbal NR consumptions and local rubber prices in Sri Lanka are not very apparent, if ACFs, PACFs and CCFs were employed on data directly. However, in the analysis, apparent relationships were able to be recognized by using the common trends depicted in Fig. 2. Consequently, Fig. 3 indicates that auction price of Ribbed Smoked Sheet (RSS) No 1 in Sri Lanka has a significant relationship between the 
consumption pattern indicated by $1^{\text {st }}$ common trend, which is a quarter behind from rubber prices. Similar types of relationships were recognized also with first and fourth common trends. There was no apparent relationship found between third common trend and Local RSS no 1 price. Further investigations are needed prior to use of these common trends as indicators, which can be used to predict RSS prices at the local market.
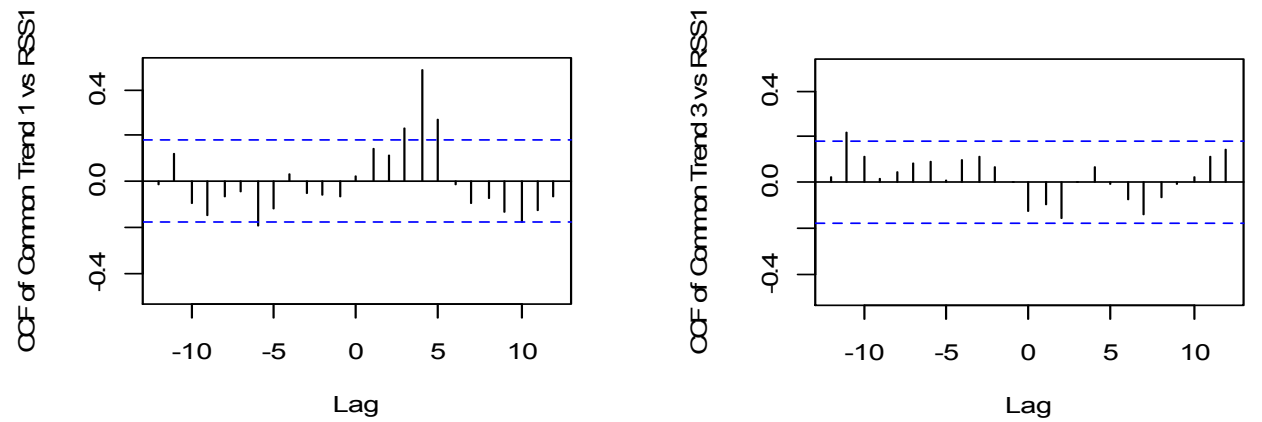

\section{Fig. 3. Cross Correlation functions (CCF) of Common trend 1 and Common trend 3 versus RSS1 prices of Sri Lanka.}

\section{Case Study III: Local NR prices}

The aim of the case study III is to provide further empirical evidences for the usefulness of $\Delta \mathrm{G}^{*}$ in testing goodness even at local level model fitting exercises. Monthly prices of different RSS grades and Latex Crepe (LC) grades for the period from 2000 to 2010 at Colombo auction were used for this study. It can be found that these grades altogether contribute more than $80 \%$ to the total annual NR production of Sri Lanka which is basically a price taking country.

Different models fitted to the data converted to their square roots and important statistics for their goodness of fit are listed in Table 6. Model with AIC of -753.07 without covariates was the best model, if the model selection was done solely on AIC. However the respective algorithm appeared unstable and only the first common trend looked interpretable. Further, it can be noticed that the number of common trends associated with this model was half of the number of time series under investigation. Hence it is fair to look at another option with less number of common trends which can be reasonably interpreted. With this background, the model with crude oil price and Colombo Consumer Price Index (CCPI) as covariates and AIC equals to -751.57 was found to be a good choice, if the model selection was done based on both AIC and $\Delta \mathrm{G}^{*}$. 
Table 6. Different DFMs fitted to auction prices of different RSS and LC grades and relevant goodness of fit statistics

\begin{tabular}{|c|c|c|c|c|c|}
\hline $\begin{array}{l}\text { Common } \\
\text { trends(M) }\end{array}$ & AIC & $\begin{array}{c}\text { Log } \\
\text { likelihood } \\
\end{array}$ & $\begin{array}{c}\text { No of } \\
\text { parameters }\end{array}$ & $\Delta \mathrm{G}^{*}$ & $p\left(\geq 2 \Delta G^{*}\right)$ \\
\hline \multicolumn{3}{|c|}{ Model I: M common trends + Noise; } & \multicolumn{3}{|c|}{$R-$ Diagonal } \\
\hline 1 & 868.78 & -404.39 & 30 & 884.18 & $<0.0000$ \\
\hline 2 & -461.74 & 269.87 & 39 & 209.92 & $<0.0000$ \\
\hline 3 & -699.43 & 396.72 & 47 & 83.07 & $<0.0000$ \\
\hline 4 & -737.94 & 422.97 & 54 & 56.82 & $<0.0000$ \\
\hline 5 & -753.07 & 488.04 & 60 & -8.25 & 0.9999 \\
\hline 6 & -742.94 & 435.97 & 65 & 43.82 & $<0.0000$ \\
\hline \multicolumn{6}{|c|}{ Model II: $M$ common trends + Explanatory variables + Noise $; R-$ Diagonal } \\
\hline 1 & 724.6 & -312.30 & 50 & 792.09 & $<0.0000$ \\
\hline 2 & 485.41 & -183.70 & 59 & 663.49 & $<0.0000$ \\
\hline 3 & 659.68 & -262.84 & 67 & 742.63 & $<0.0000$ \\
\hline \multicolumn{6}{|c|}{ 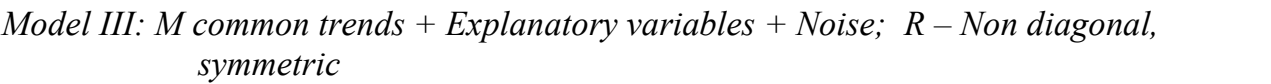 } \\
\hline 1 & -652.49 & 421.25 & 95 & 58.54 & $<0.0000$ \\
\hline $\mathrm{b}_{2}$ & -751.57 & 479.79 & 104 & 0 & \\
\hline 3 & -733.9 & 478.95 & 112 & 0.84 & 0.9999 \\
\hline \multicolumn{6}{|c|}{ Model IV: M common trends + Noise; $R-$ Non diagonal, symmetric } \\
\hline 1 & -546.56 & 348.29 & 75 & 131.5 & $<0.0000$ \\
\hline 2 & -666.49 & 427.25 & 84 & 52.54 & $<0.0000$ \\
\hline 3 & -718.49 & 451.25 & 92 & 28.54 & 0.0015 \\
\hline 4 & -719.11 & 458.56 & 99 & 21.23 & 0.0007 \\
\hline 5 & -717.73 & 448.75 & 105 & 31.04 & $<0.0000$ \\
\hline
\end{tabular}

${ }^{\mathrm{b}}$ selected as best fitted model., $\Delta \mathrm{G} *$ is defined as the change of log likelihood between the selected model and the other models

Further, these common trends are reasonably interpretable. Fig. 4 depicts particular common trends, while relevant factor loading are listed in Table 7.

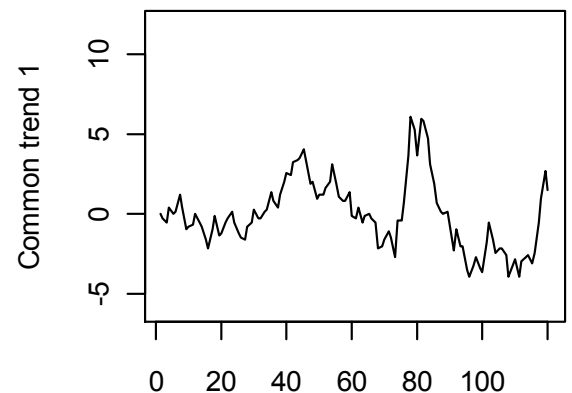

Time (months from Jan 2000)

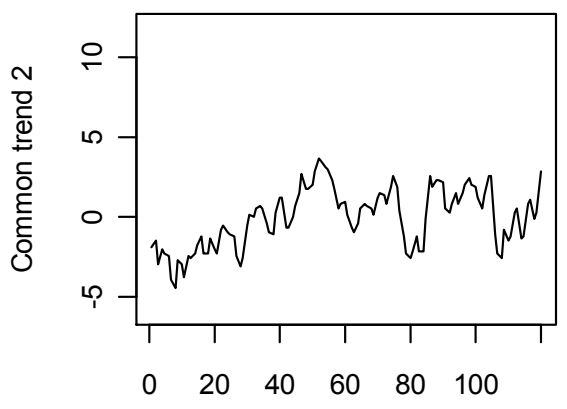

Time (months from Jan 2000)

Fig. 4. Common trends obtained from the best fitted model, with Crude oil price and CCPI as explanatory variables and $\mathrm{H}$ is a diagonal matrix. 
Table 7. Factor loadings of respective common trends in the best fit models for auction prices of RSS and LC grades in Sri Lanka

\begin{tabular}{ccc}
\hline Commodity & Common Trend 1 & Common Trend 2 \\
\hline RSS1 & 0.287 & 0.282 \\
RSS2 & 0.264 & 0.304 \\
RSS3 & 0.266 & 0.310 \\
RSS4 & 0.261 & 0.312 \\
RSS5 & 0.241 & 0.323 \\
LC-1X & 0.588 & 0.102 \\
LC-1 & 0.563 & 0.145 \\
LC-2 & 0.520 & 0.196 \\
LC-3 & 0.495 & 0.225 \\
LC-4 & 0.362 & 0.288 \\
\hline
\end{tabular}

All rubber grades provided positive loads to the $1^{\text {st }}$ common trend, with LC grades contributed more compared to the contribution by RSS grades. The behavioral pattern of common trend 1 was very similar to that of the difference between average RSS prices and LC prices. The correlation coefficient between them was about 0.99 . RSS types add more to the second common trends in prices compared to LC grades. However, it can be inferred that this provides an indication about the general trend of rubber prices, once they were standardized for crude oil prices and world production of NR. It is important to notice that crude oil prices at international market prices and average RSS prices and LC prices have a very similar pattern over time.

Regression parameters of two covariates in the selected DFM, their standard errors (s.e) and $t$ values are listed in Table 8 . It can be observed that both covariates are statistically significant at each grade.

Table 8. Regression parameters of explanatory variables in DFM fitted to local rubber prices

\begin{tabular}{lccccccccc}
\hline \multirow{2}{*}{ Grade } & \multicolumn{3}{c}{ Constant } & \multicolumn{4}{c}{ Crude oil price } & \multicolumn{3}{c}{ CCPI } \\
\cline { 2 - 9 } & Coef. & s.e & $\begin{array}{c}\mathbf{t} \\
\text { value }\end{array}$ & Coef. & s.e & t value & Coef. & s.e & t value \\
\hline RSS1 & -4.53 & 0.70 & $-6.47^{* *}$ & 0.81 & 0.09 & $8.79^{* *}$ & 0.15 & 0.02 & $6.72^{* *}$ \\
RSS2 & -4.43 & 0.77 & $-5.78^{* *}$ & 0.80 & 0.09 & $8.61^{* *}$ & 0.15 & 0.02 & $6.4^{* *} 7$ \\
RSS3 & -4.54 & 0.79 & $-5.75^{* *}$ & 0.76 & 0.09 & $8.07^{* *}$ & 0.16 & 0.02 & $6.48^{* *}$ \\
RSS4 & -4.48 & 0.80 & $-5.58^{* *}$ & 0.80 & 0.09 & $8.57^{* *}$ & 0.15 & 0.02 & $6.17^{* *}$ \\
RSS5 & -4.31 & 0.86 & $-5.01^{*}$ & 0.79 & 0.09 & $8.41^{* *}$ & 0.15 & 0.02 & $5.89^{* *}$ \\
LCX & -5.25 & 1.15 & $-4.55^{*}$ & 0.93 & 0.13 & $6.93^{* *}$ & 0.16 & 0.03 & $4.69^{*}$ \\
LC1 & -4.84 & 1.03 & $-4.71^{*}$ & 0.95 & 0.13 & $7.26^{* *}$ & 0.15 & 0.03 & $4.60^{*}$ \\
LC2 & -4.50 & 0.89 & $-5.08^{*}$ & 0.96 & 0.13 & $7.52^{* *}$ & 0.14 & 0.03 & $4.62^{*}$ \\
LC3 & -4.28 & 0.83 & $-5.14^{*}$ & 0.96 & 0.12 & $7.65^{* *}$ & 0.14 & 0.03 & $4.57^{*}$ \\
LC4 & -4.56 & 0.71 & $-6.41^{* *}$ & 0.94 & 0.11 & $8.88^{* *}$ & 0.14 & 0.03 & $5.32^{*}$ \\
\hline
\end{tabular}

* $-\mathrm{p}<0.05, * *-\mathrm{p}<0.01, * * *-\mathrm{p}<0.001$ 


\section{Case Study IV. Rubber prices at International markets:}

Rubber prices at the Colombo auction are usually related to one month lagged international NR prices (Wijesuriya, 1998). That means price at the international market are shown off one month later by the auction prices at the Colombo market. However, present rubber prices at Colombo looks sensitive to the international market prices within the same month as depicted in Fig. 4. With this background, DFM model can be used to identify which international markets are linked with price fluctuations at Colombo market. Further, it can be used as an aid to check the relationship depicted in Fig. 5, which is different from the claim by Wijesuriya (1998).
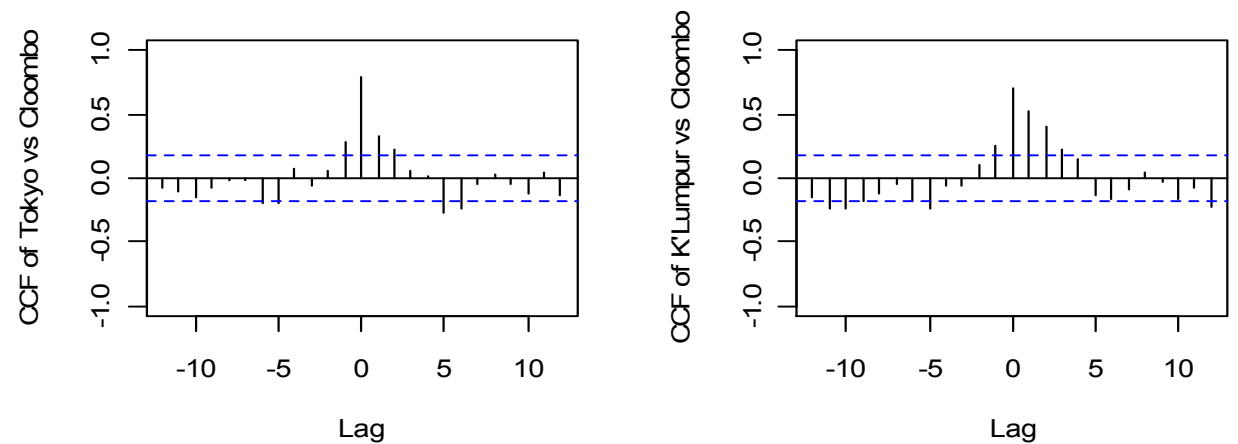

Fig. 5. Cross Correlation Functions fitted to monthly prices at Tokyo and K' Lumpur market versus monthly NR prices at the Colombo auction

A DFM was fitted to international prices at different markets adopting proposed strategies for model selection. It was found that a model with two common trends and symmetric nondiagonal $\mathrm{R}$ was the best fit model. Further it included crude oil price and world NR consumption as explanatory variables. Relevant common trends are depicted in Fig. 6, while factor loadings are listed in Table 9, respectively. New York market and K' Lumpur market contributed more to the first common trend meanwhile Tokyo and London markets added more weights to the second common trend. Regression coefficient associated with each explanatory variable included in the model, standard errors and t values are listed in Table 10. It is inferred that NR consumption and crude oil price have statistically significant relationships with NR prices in different markets under investigation.
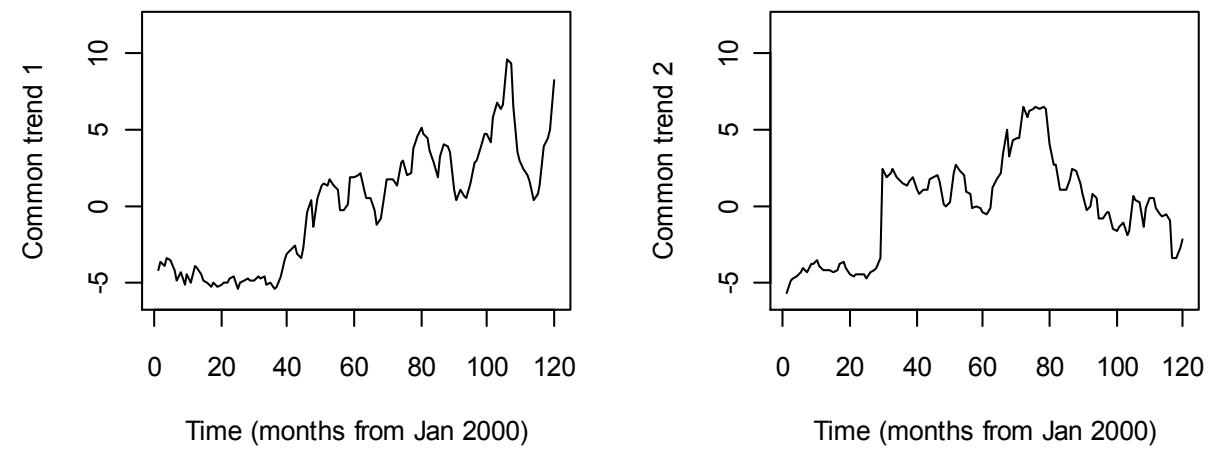

Fig. 6. Common trends identified by the DFM fitted to NR prices at different markets 
Table 9. Factor loadings of respective common trends in the best fit models to NR prices at different markets

\begin{tabular}{lcc}
\hline Variable & Common trend 1 & Common trend 2 \\
\hline New York & 0.067 & 0.036 \\
London & 0.035 & 0.124 \\
Tokyo & 0.015 & 0.081 \\
K' Lumpur & 0.122 & 0.034 \\
\hline
\end{tabular}

Table 10. Regression parameters of explanatory variables included in DFM fitted to prices in different international markets

\begin{tabular}{lccccccccc}
\hline \multirow{2}{*}{ Country } & \multicolumn{3}{c}{ Constant } & \multicolumn{3}{c}{$\begin{array}{c}\text { World consumption of } \\
\text { NR }\end{array}$} & \multicolumn{2}{c}{ Crude Oil Price } \\
\cline { 2 - 10 } & Coef. & s.e & t value & Coef. & s.e & t value & Coef. & s.e & t value \\
\hline \multirow{2}{*}{ New York } & -0.04 & 0.18 & -0.34 & 0. & 0.04 & $2.10^{*}$ & 0.60 & 0.05 & $12.05^{* * *}$ \\
London & -0.03 & 0.33 & -0.18 & 0.08 & 0.05 & $1.70^{*}$ & 0.53 & 0.07 & $6.88^{* * *}$ \\
Tokyo & -0.01 & 0.21 & -0.03 & 0.07 & 0.06 & 1.17 & 0.74 & 0.07 & $10.84^{* * *}$ \\
K' Lumpur & -0.07 & 0.28 & -0.28 & 0.08 & 0.03 & $2.23^{* *}$ & 0.43 & 0.06 & $7.69^{* * *}$ \\
\hline
\end{tabular}

$*$ - $\mathrm{p}<0.05, * *-\mathrm{p}<0.01, * * *-\mathrm{p}<0.001$

CCFs fitted to common trends is depicted in Fig. 6 while, these trends versus NR prices at Colombo auction are illustrated in Fig. 7. It reveals that NR prices at the Colombo auction are one month lag behind the NR prices at Yew York market and K' Lumpur market, which have been standardized for crude oil price at the international market and world demand for NR. Further, this confirms the results obtained by Wijesuriya (1998). As a result, it can be inferred that the immediate fluctuations of prices at Colombo auction (Fig. 5) may be a consequence of fluctuations in crude oil prices and world demand for NR.
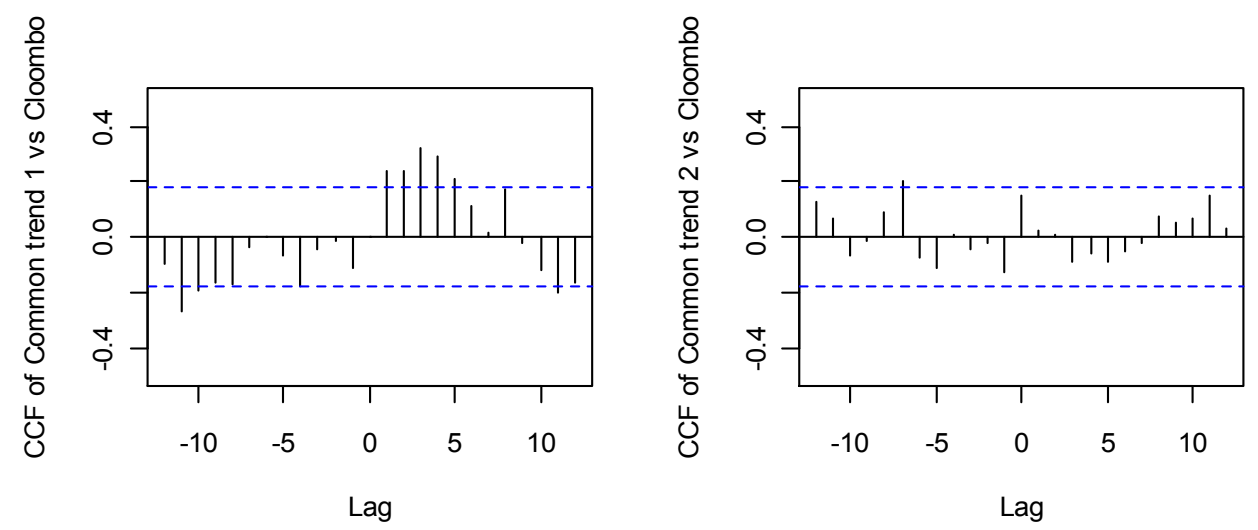

Fig. 7. CCFs fitted to common trends in Fig. 6 versus NR prices at Colombo auction

In case study I, the same model was selected based on both goodness of fit measures, AIC and $\Delta \mathrm{G}^{*}$. However, in other case studies, there were some issues with the stability of the algorithm and/ or interpretability of the underlying common trends of DFMs selected based on AIC. In this context, $\Delta \mathrm{G}^{*}$ has provided a statistically sound basis to identify a model 
which is more stable and interpretable. Eventually, it is clear that above case studies provide clear empirical evidence for the usefulness of $\Delta \mathrm{G}^{*}$ as a measure of goodness of fit of the DFM. Moreover, it should be emphasized that further signs of lack of fit and violations of underlying assumptions associated with the selected DFM need to be diagnosed. It is very important to check for the departures from the expect normal distributions of $u_{t}$ and $v_{t}$. This is usually achieved by careful investigation of residuals of DFM.

It was found that DFMs were lack of fit, if they were directly fitted to local NR price series together with crude oil price and CCPI as covariates. Further, evidence for stochastic volatility in those time series were apparent in particular residual plots either explanatory variables were excluded or included in the model. Further, there were some apparent patterns (trends) found in some of these residual plots indicating the lack of fit of particular models, where the DFM consisted of two common trends with symmetric non-diagonal R. It was further noticed that particular algorithms were very unstable in the presence of this kind of issues. However, this problem was solved, when model fitting was done with the data transformed into their squarer roots. The algorithm also was very stable. However, such issues were not reported in other case studies. Normality of errors was checked with normal probability plots and there were no evidence reported for the departures form underlying distributions. Eventually, for all instances, the algorithm appeared more stable, if model fitting was done with normalized data. Structure of the covariance matrix found in both factor analysis and DFA are in the similar form i.e. $\Lambda \Lambda^{\prime}+\mathrm{R}$. It is a common question whether factors found in factor analysis are really exist and there are evidences that some populations do not have covariance which does not follow above mentioned structure, unless M (number of factors) is large (Rencher, 2002). Similar problem can exist with DFA where the number of common trends needs to be minimized without loss of much information.

\section{CONCLUSIONS}

This study provides clear empirical evidence that goodness of fit of a DFM can be evaluated by testing the significance of the additional likelihood given by the model compared to rest of DFMs. In the first place, it is recommend choosing a set of models fitted under each category viz. models with no covariates and diagonal $\mathrm{R}$, models with no covariates and symmetric non-diagonal $\mathrm{R}$, models with covariates and diagonal $\mathrm{R}$, and models with covariates and symmetric non-diagonal $\mathrm{R}$, by evaluating them with AIC as a criterion that measure the lack of fit. These models should be further evaluated by $\Delta \mathrm{G}^{*}$ until a model with fair number of meaningful common trends is found. The use of AIC is very important at the initial model selection, since it compromises the number of parameters and the likelihood of the model. The use of $\Delta \mathrm{G}^{*}$ is vital especially in the choice of a model with minimum number of common trends which have fair interpretations.

DFM is useful in identifying countries with similar production patters of an agricultural commodity. Evidence of common trends and seasonal behaviors of NR production in major rubber growing countries can be taken into account especially for selection of models in future studies on forecasting. In general it can be inferred that there is a continuous growth in the global production of the NR.

The second case study provides very clear evidence that consumption of the NR by early developed countries such as USA, Japan, Germany and France are getting deteriorated while 
NR consumption in rubber producing countries viz. China, India, Malaysia and Thailand is on the increase. This is an indication that rubber producing countries tempt to improve rubber based industries to produce value added rubber products rather than exporting NR as a raw material. The impact of world rubber consumption is immediate on rubber prices in Sri Lanka regardless of any fluctuations in the crude oil prices in the international market.

The positive impacts of the changes in global NR consumption and international crude oil prices on the rubber prices at different international markets are very apparent. It can be found that there exist some draw backs in the London and Tokyo rubber markets while New York and $\mathrm{K}^{\prime}$ Lumpur rubber markets indicate continuous growths regardless of the continuous growth in NR consumption and crude oil prices at the international market. However, further economic research is needed before coming to a firm conclusion on this matter. New York market and K' Lumpur market have influences on local rubber prices in Sri Lanka, while there is no apparent relationship of rubber prices in the Colombo market with the prices in London and Tokyo markets. However, the impacts of the identified international markets will appear a month later on the local rubber prices unless there is no fluctuation in international NR consumption and crude oil prices. In general it can be concluded that there is a very clear positive relationship between crude oil prices, NR prices and NR consumption.

It is very clear that underlying common trends in demand, supply and prices in the rubber sector can be usefully identified by the DFM. However, further researches with strong background in economics are needed to validate and improve the interpretability of these results further. Some researchers are encouraged to explore the possibilities of using some of the common trends resulting from this study as indicators in forecasting local rubber prices. Further research is encouraged on determination of the number of common trends in DFM, impact of other possible model forms in DFA, impact of different forms of R on DFA and impact of different factor rotations in DFA which will further improve the underlying theory and applicability of DFM.

\section{REFERENCES}

Akaike, H, (1987). Factor analysis and AIC. Psychometrika , 52(3), 317-332

Chatfield, C., (2000). Time series Forecasting. Chapman \& Hall, CRC press, Landon.

Durbin, J. and Koopman, S.J. (2004). Time Series analysis by State Space Methods. Oxford statistical science series 24, Oxford University Press, UK.

IRSG, (2001:2010). Rubber Statistical Bulletin. International Rubber Study Group, Wembley, UK. 55:65. [on line]. [Accessed on 02.10.2011] available at http:// www.rubberstudy.com

Macho, F.J.F. (1997). A dynamic factor model for economic time series. Kybernetika, 33(6), 583:606.

Molenaar, P.C.M., de Gooijer, J.G. and Schmitz, B. (1992). Dynamic factor analysis of nonstationary multivariate time series. Psychometrika. 57, 333-349. 
Priestley, M.B. (1981). Spectral Analysis and Time Series Analysis. Academic Press: London.

Rencher, A.C. (2002). Methods of Multivariate Analysis $2^{\text {nd }}$ ed.. Wiley series in probability and statistics, Jhon Wiley \& Sons Inc., USA.

Rice, J.A. (2007). Mathematical Statistics and data Analysis $3^{\text {rd }}$ ed.. Duxbury advance series, Thomson Higher Education, Belmont, CA: Duxbury.

Shumway, R.H. and Stoffer, D.S. (1982). An approach to time series smoothing and forecasting using the EM algorithm. J. Time Series Analysis. 3, 253-264.

Shumway, R.H. and Stoffer, D.S. 2006. Time Series Analysis and Its Applications: with R Examples, Springer Science+Business Media, New York, USA.

Wijesuriya, W. (1997). Design techniques and analysis of experiments on rubber (Hevia brasiliensis). MPhil thesis, Postgraduate Institute of Agriculture, University of Peradeniya, Sri Lanka.

Zuur, A.F., Fryer, R.J., Jolliffe, I.T., Dekker R. and Beukema J.J. (2003). Estimating common trends in multivariate time series using dynamic factor analysis, Environmetrics, $14,665-685$. 